\title{
High-Capacity Transport Associated with Pre- and Post-Haulage in Intermodal Road-Rail Transport
}

\author{
Ying Ye, Jiali Shen, Rickard Bergqvist* \\ Industrial and Financial Management \& Logistics, Department of Business Administration, School of Business, \\ Economics and Law, University of Gothenburg, Göteborg, Sweden \\ Email: "rickard.bergqvist@gu.se
}

Received 23 May 2014; revised 21 June 2014; accepted 15 July 2014

Copyright (C) 2014 by authors and Scientific Research Publishing Inc.

This work is licensed under the Creative Commons Attribution International License (CC BY). http://creativecommons.org/licenses/by/4.0/

c) (i) Open Access

\section{Abstract}

This paper develops a model for analyzing the potential of longer and heavier vehicles (LHVs) related to pre- and post-haulage in the intermodal rail-road transport chain (IRT). The paper considers the combined economic and emission costs among three different transport networks including intermodal rail-road transport with current Swedish regulatory framework for trucks, intermodal rail-road transport with LHVs, and direct-road transport. The objective is to analyse the potential of high-capacity transport associated with pre- and post-haulage for enhancing the competitiveness of intermodal transport from a full-costs perspective. The model developed is applied to a Swedish context and case study. Research findings reveal that the break-even of the IRT compared to the direct road transport could be significantly lowered, which suggests the LHVs contribute to exploring the market of IRT over smaller flows.

\section{Keywords}

Intermodal Transport, HCT, Sustainable Transport, Pre- and Post-Haulage, Modal Shift

\section{Introduction}

Transport is a fundamental factor to the economy and society, and today more attention is given to improving the efficiency and cutting the external cost of logistics. The two most notable improvement projects related to transport in Europe are intermodal transport and High Capacity Transport (HCT). High Capacity Transport is a term used for vehicle combinations that exceed existing regulations on either length and/or weight. This paper

*Corresponding author.

How to cite this paper: Ye, Y., Shen, J.L. and Bergqvist, R. (2014) High-Capacity Transport Associated with Pre- and PostHaulage in Intermodal Road-Rail Transport. Journal of Transportation Technologies, 4, 289-301. 
aims at analyzing the potential of HCT in pre- and post-haulage (PPH) in road-rail intermodal transport.

In Europe, intermodal freight transport has frequently been seen as a potentially strong competitor to road transportation and environmentally friendlier in many contexts [1]. According to UIC [2], compared to pure road transport, intermodal rail-based transport is reducing the external costs (i.e., emissions of greenhouse gases and unpaid costs to society for accidents) by $€ 0.02$ per tonne-km. Consequently in 2007, the European Commission adopted a Freight Transport Logistics Action Plan. This includes potential wider use of European Modular System (EMS) vehicle combinations of 25.25 meters long. These vehicles are in regular use in Sweden and Finland (recently Finland is testing HCT vehicle combinations of 32 meters long) [1]. Broad-based utilization of LHVs in Sweden would provide significant benefits in terms of increased efficiency, as well as reduced demand for investments to lower fuel consumption and reduce emissions. Furthermore, in Sweden, considerable research addresses longer vehicles, which are up to $32 \mathrm{~m}$ long and capable of carrying two $40 \mathrm{ft}$ containers simultaneously. These studies indicate that there is a huge potential to be more fuel efficient and environmentally friendly.

However, the increase of transport demand in Europe is mainly met by road transport [3], which leads to significant negative impacts on society, especially the environment [4]. The main reason is that the direct-road transportation has strong competition in the transport market over short distance, which is the main market in the EU (about $46 \%$ of the demand over distances of 150 - $500 \mathrm{~km}$ ). Furthermore, the intermodal rail-truck transport is associated with long-distance transport that accounts for only $22 \%$ of the demand for transport in the EU. According to the European Commission [5], road freight transport accounts for $73 \%$ of all inland freight transport in the EU. Therefore, considering the negative impacts from road transport, the white paper of transport in the EU (2011) suggests that " $30 \%$ of road freight over $300 \mathrm{~km}$ should shift to other modes such as rail or waterborne transport by 2030 , and more than $50 \%$ by 2050 ”. This goal requires the development of the competitiveness of IRT transport, especially the economic competitiveness.

There is a great deal of research addressing this challenge. The competitiveness of IRT transport reported by much of the research depends on the costs of transshipment and the pre- and post-haulage (PPH) which accounts for $25 \%-40 \%$ of the total cost of the IRT system [6]-[8]. For this reason, this paper would like to measure the potential of lowering the cost of PPH as it relates to the intermodal transport chain. In addition, many other researches maintain that the size and weight of trucks limit the development of the road freight transport segment in the IRT system. Bergqvist and Behrends [4] suggest using longer vehicles that have a substantial potential to reduce the cost of PPH. Thus longer and heavier vehicles seem to be a potential solution to reduce the cost of the IRT system. The purpose of this paper is to develop a model for analyzing the potential of longer and heavier vehicles related to pre- and post-haulage in the rail-truck intermodal transport chain. Using the case of Jula in Sweden and the developed model, the paper estimates the benefits achieved by shifting truck type from the Swedish current truck regulations to the longer ones with $32 \mathrm{~m}$ length. This dispensation for longer vehicles could enable a competitive intermodal solution between Gothenburg harbor, Falköping intermodal terminal, and Jula's central warehouse in Skara.

The following section addresses previous research on PPH and LHVs. Section 2 relates to PPH and IRT and Section 3 develops the cost calculation for different transport networks. Section 4 gives an analysis of the results after the application of the model using the case data. And finally, conclusions are presented in Section 5.

\section{Literature Review}

Two streams of research that study the role of PPH related to intermodal rail-road transport and the effect of the LHVs are associated with this paper.

\subsection{PPH Related to Intermodal Rail-Road Transport}

Since 1990 a substantial amount of research are addressing intermodal freight transport issues. Therefore, there are many definitions of intermodal freight transport and there is little consensus [9]. The definition of intermodal freight transportation according to the United Nations Economic Commission for Europe is used for this research:

"The movement of goods in one and the same loading unit or road vehicle, which uses successively two or more modes of transport, without moving the goods itself in changing modes" [10].

Accordingly, intermodal rail-road freight (IRT) transport combined the two modes in which road transport is 
used in the short-haul transit for collection or delivery, while rail transport is related to the long-haul transport [11]. In this definition, loading unit is "a consignment of freight-invariably, but not always, comprising a combination of small consignments, as in a group age load, which is unitized to save trans-shipment and repacking time and cost at each individual stage of the journey, and also for ease of handling [12]". The same loading unit means a standard loading unit that is related to an ISO container or other swap bodies that are internationally recognized.

There is little in the literature that clearly defines PPH. However, the PPH activities are easy to understand. The activities of PPH in an IRT system are always performed by trucks in the initial and final legs of the IRT, which we mentioned in the category of drayage [12]. Figure 1 is a model of IRT activities, which shows the clear role of PPH, transshipment, and rail haulage [13]. The core activities of IRT are transshipment, rail haulage, coordination activities, and PPH [13], which include the operations of the intermodal loading unit (ILU) from the time it is filled until it is emptied [14].

PPH plays an important role in IRT. In fact, few IRT systems operate without taking PPH as their initial and final legs [12]. The flexibility and convenience of PPH that takes place by truck is unmatched by any other mode. The truck can go almost everywhere and is significantly competitive in the short-distance transport demand. In Europe, the distance of most PPH operations around inland terminals is 0 - $25 \mathrm{~km}$, with only a few cases over a longer distance than $100 \mathrm{~km}$ [15]. Therefore it is the most predominant modal choice in the PPH operation. However, the cost of PPH is also comparably high.

$\mathrm{PPH}$ accounts for about $25 \%$ to $40 \%$ of the transport costs, despite the distance of PPH being significantly shorter compared with rail haulage [9]. The PPH costs even account for more than $70 \%$ of the total costs over a distance of about $300 \mathrm{~km}$ in some cases [16]. Generally speaking, the shorter the transport distance, the higher the proportion of PPH costs of total costs. The cost of transshipment accounts for another $20 \%$ of the transport costs [13]. Therefore, Ballisand Golias [6] [7] and Niérat [8] pointed out that the competitiveness of IRT transport highly depends on the costs of the PPH and transshipment operations. PPH and transshipment operations, therefore, seriously affect profitability and competition of IRT [4]. This feature makes the IRT transport more suitable for large flows over longer distances because of the high fixed costs of terminals and PPH [17]. Over distances of less than $400 \mathrm{~km}$, the competitiveness is generally low for IRT transport compared with unimodal road service [18]. Bärthel and Woxenius [17] specified that long distance transport accounts for only $22 \%$ of the demand for transport in the EU, while $46 \%$ of the demand is over distances of 150 - $500 \mathrm{~km}$, which falls into the category of short-distance transport. This situation makes the direct-road transport more competitive in comparison with the IRT transport. Much research focuses on resolving this conflict by making IRT transport suitable for smaller flows over short distances. According to some research, reducing the PPH cost by $30 \%$ can decrease the break-even distance of intermodal transport compared with direct road by $40 \%$ [19]. Kim and Van [20] reported that reducing PPH cost is an effective way to decrease the intermodal break-even and increase the intermodal mode share at the same time, suggesting that better PPH operation is the key for short-distance IRT market gain.

\subsection{The Effects of LHVs}

The size of trucks plays an important role in PPH operations. There are significant operational differences

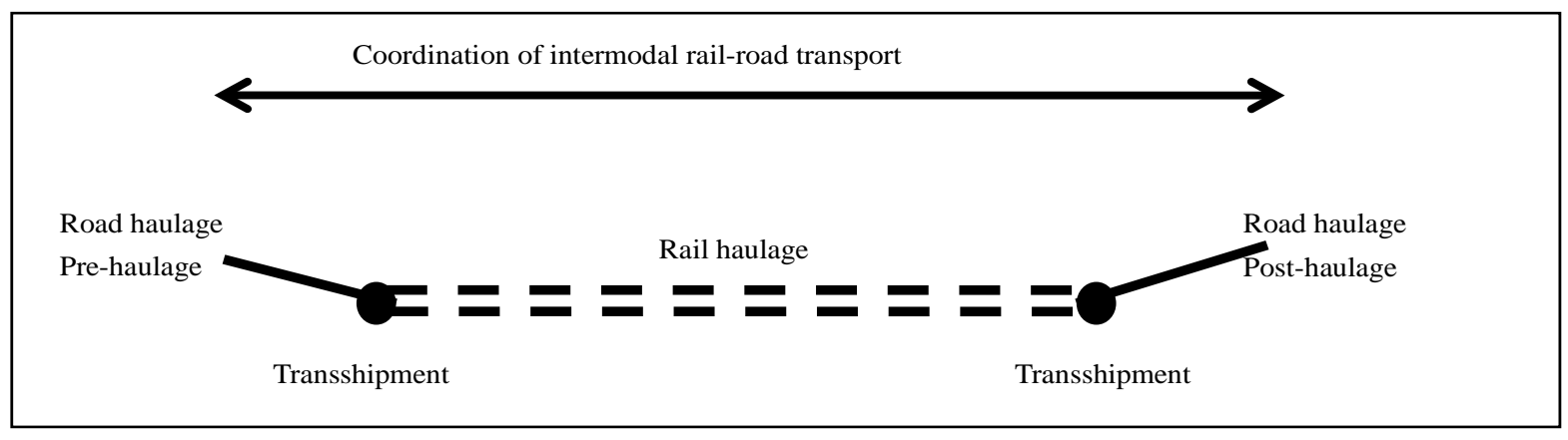

Figure 1. A system model focusing on activities in the intermodal chain. Source: Modified from Woxenius \& Bärthel [13]. 
between different vehicle types for PPH and intermodal transport. The most significant dimension lies in the length of the truck, which is related to how many containers or swap bodies can be carried per vehicle [12]. The size of the vehicles greatly influences the costs of the PPH. Bärtheland and Woxenius [17] used the Swedish truck as an example to demonstrate that high-capacity trucks significantly decrease the average haulage costs. Meanwhile, Bergqvist and Behrends [4] illustrated that longer vehicles with $32 \mathrm{~m}$ length had a substantial potential to decrease the cost of PPH. Trip and Bontekoning [21] indicated that it was possible to integrate small freight flows by "getting higher degree of loading, a higher frequency and a larger geographical coverage of the network" by applying a new terminal operations concept in specific cases.

The EU defines longer and heavier vehicles (LHVs) as "all freight vehicles exceeding the limits on weight and dimensions established in Directive 96/53/EC” [22]. The LHVs in the EU generally refer to the Lorries, which are 25.25 meters in length and 60 tonnes gross mass [1]. These LHVs, which are used in Sweden and Finland, are also used under trial conditions in Belgium, Denmark, Germany, and the Netherlands [1] [22]. Currently, the European Commission has begun to review the case of allowing the use of LHVs and several governments are considering the implications in order to deal with the increasing road congestion and environmental problems. For the purpose of this paper, the LHVs we want to introduce are longer trucks that have a maximum length of 32 meters and a maximum gross weight of 60 tonnes and are expected to carry $2 \times 40 \mathrm{ft}$ or even $2 \times 45 \mathrm{ft}$ containers simultaneously.

According to research, based on available data, changing the current trucks in the EU to LHVs will reduce the road transport cost by approximately $15 \%$ to $30 \%$ on average [22] [23]. Secondly, the LHVs will cause a mode shift from rail to road by about 5\% - 18\% [23] [24]. With regard to the environment, De Ceuster [23] reported LHVs (60 t) were not only more efficient in fuel consumed per ton-km than the standard ones but also contributed to the reduction of $\mathrm{CO}^{2}$ emissions by $3.58 \%$, NOx emissions by $4.03 \%$, and PM by $8.39 \%$. Moreover, it was recognized that the number of vehicle-kms would be reduced to move the same amount of goods because of the greater loading weights, which suggested a likely increase in traffic safety [25]. With regard to infrastructure, the LHVs significantly increase the stress on bridges, which may increase the cost around $€ 4$ - $€ 8$ billion in the EU [26]. From the literature review, there is no direct evidence that proves the LHVs would lead to negative consequences in the aspects of safety and environment. However, there is a possibility that plenty of the rail transport would shift to road if LHVs are allowed. In sum, current research has not gained a conclusive answer whether the LHVs are feasible or not. But all of the researches above mention LHVs as highly capable of improving the efficiency of road transport, thereby reducing the cost of road transport. In the context of the case of Jula, the term LHV corresponds to the capacity 4 TEU.

\section{Cost Calculation Model}

\subsection{Cost Structure}

Through a transport system, there are internal and external costs associated with cargo movements. Internal costs usually refer to the operation costs [27] and in this paper relate to the economic cost of moving units from origin to destination. In addition, the transport system imposes the external costs on society, which includes congestion costs, environmental costs, and accident costs as well as other external costs [27]. Therefore, this paper will consider both economic costs and environmental costs when calculating the performance of the different scenarios.

\subsubsection{Economic Costs}

The internal costs of the transport network are determined by all the operations associated with the movements of goods from production to consumption as shown in Table 1 [27]. Daganzo [28] pointed out these operations incur costs related to motion and "holding". The motion costs are the costs derived from the handling and transport while the holding costs refer to the waiting time costs. This paper only considers the motion costs, which are so-called economic costs according to the situation of the case studied.

The economic costs in this paper refer to the direct costs of the company. There are various cost components as shown by Daganzo [28]. When it comes to calculating the costs, the cost structure can also be divided into fixed costs and variable costs [29]. Flodén [29] also pointed out that the division was completely dependent on the time period. Many fixed costs are also shared costs such as overhead costs, and some of the variable costs are considered as fixed costs in many calculations such as vehicle taxes. When calculating the economic costs of 
Table 1. The activities of the cargo moved from production to consumption.

$\begin{array}{ll}\text { - } & \text { carried from the production area to a storage area } \\ \text { - } & \text { stalled until a vehicle becomes available in storage area } \\ \text { - } & \text { loaded into a vehicle } \\ \text { - } \quad \text { transported to the destination } \\ \text { - } \quad \text { unloaded, handled, and held for consumption at the destination }\end{array}$

Source: Daganzo (2005), p. 30.

the company, this paper will consider the costs from the company perspective as well. The costs also can be counted by the items including the cost of vehicle taxes, insurance, salary, repair, overhead costs, fuel cost, taxes, and so on. To calculate the costs, this paper will classify these cost items into fixed costs and variable costs.

\subsubsection{External Costs}

The external costs refer to "those costs that are incurred by other parties as a result of an operator's transport or terminal activities" [30]. The general external costs include the five groups of costs of "air emissions, accidents, noise, global warming and congestion [30]". The moving of the vehicles usually causes air emissions called air pollution that results in damage to people's health and the environment. The traffic accidents lead to the damage of the affected people and are considered in each operation step due to the different frequency, character of occurrence, and consequences in the transport system [27]. The congestion will significantly increase the time costs of the traffic network and incur the external emission. The noise and congestion are usually considered in the operations of collection and distribution in urban areas. This paper will only consider the costs of air emissions.

The external costs of the operation depend on three factors that are "the scale of the initial production of emissions, the physical impact of these emissions such as the damage of the health and delay and finally the valuation of these impacts [30]". There are many research outcomes that contribute to evaluation of the external cost of different transport modes and the monetary values of the environment costs. Coincidentally, there are numerous Internet calculators used to identify the environmental impacts of a freight operation. To clearly state the costs, we will place monetary values on the environment costs, which mean a conversion of physical impacts into the common economic metric. The valuation will be based on the previous estimates built by the researchers. The structure to calculate external costs of the intermodal system in this paper is to summary is each section of the traffic network, with the economic costs similarly calculated.

\subsubsection{Cost Calculation Structure}

According to Daganzo [28], the costs of the transport can be generally described as:

$$
C_{\text {total }}=C_{\mathrm{f}}+C_{\mathrm{v}} \times v \times d
$$

where $C_{\text {total }}$ is the total cost of the transport, $C_{\mathrm{f}}$ is the fixed cost per shipment, $c_{\mathrm{v}}$ is the rate of variable cost increased per shipment size, $v$ is the volume of the cargo, and $d$ is the transport distance. Considering the case scenarios, the total economic cost of the intermodal system can be divided into the cost of the rail haulage, handling, and the road haulage.

Daganzo [28] reported that if one used a public carrier to transport the cargo, the total costs were the sum of each transfer unit. Consequently, the costs of rail-haulage in this case depend on the volume and distance and the mathematical relationship is:

$$
C_{\text {rail-haulage }}=c_{\mathrm{f}-\text { rail }}+C_{\mathrm{v} \text {-rail }} \times v \times d_{\text {railway }}
$$

where $C_{\text {rail-haulage }}$ is the total cost of the railway transport, $c_{\mathrm{v}}$ is the rate of variable cost increased per shipment size, $c_{\mathrm{f} \text {-rail }}$ is the fixed cost for rail transport, $v$ is the volume of the cargo, and $d_{\text {railway }}$ is the distance of the railway haulage (see Table A1 for details on railway cost parameters).

The costs of road can be calculated in the same way. As the road haulage is operated by the company, the costs of salary and general overhead costs are regarded as fixed costs. And the fixed costs are assumed to be just 
related with the number of shipments.

$$
C_{\text {road }}=c_{\text {f-road }}+c_{\text {v-road }} \times v \times d_{\text {road }}
$$

where $C_{\text {road }}$ is total cost of the road haulage, the $c_{\mathrm{f} \text {-road }}$ is the fixed cost of the road.

Handling costs are incurred by the operations of loading and unloading the ILUs. The handling costs depend on the cargo flow:

$$
C_{\text {handling }}=c_{\text {v-handling }} \times V
$$

where $C_{\text {handling }}$ is the cost of handling that happened in the terminal, $c_{v}$ is the rate of variable cost of handling per loading unit, and $V$ is the total volume of the cargo.

Therefore, the final economic costs are the sum of the costs mentioned above and the mathematical relationship is:

$$
C_{\text {total }}=C_{\text {rail-haulage }}+C_{\text {road }}+C_{\text {handling }}
$$

This is the structure to calculate costs of the intermodal system in this thesis.

\subsection{The Calculation Modal}

Given the components illustrated above, the calculation of the cost of the transport network is constructed in Table 2.

Where $C_{\text {rail-haulage }}$ is the total operating cost of the rail transport section; $c_{\mathrm{f}}$ is the fixed cost; $h$ is the number of hours associated with the operation; $c_{\mathrm{V}}$ is the rate of variable cost of each item; $i$ is the number of types of fixed costs; $\mathrm{j}$ is the number of the types of the variable items; $d_{\text {rail }}$ is the distance of the rail haulage; $c_{\mathrm{fr} 1}, c_{\mathrm{fr} 2}, c_{\mathrm{vr} 1}, c_{\mathrm{vr} 2}$, $c_{\mathrm{vr} 3}, c_{\mathrm{vr} 4}, c_{\mathrm{vr} 5}, c_{\mathrm{vr} 6}$ respectively refer to the different items of the costs of the rail haulage and the rate is given; $n_{\text {train }}$ is the number of the trains required depending on the scale of cargo; $w$ is the gross weight; $a$ is the charge of electricity consumption, which is $0.0212 \mathrm{KWH}$ per gross tonne published by the Swedish Transport Administration; $t$ is the number of train holding hours per operating day(assumed $24 \mathrm{~h}$ per day); $d_{\text {operation }}$ is the day of operating train assumed to be 53 days per year since one day per week according to the case; $V_{\text {TEU }}$ is the total volume per year (TEU); $n_{\mathrm{TEU}}$ is the average shipment size for the train assumed to be 45 TEU per train; $w_{\mathrm{ac}}$ is the average weight per TEU, which is 5.7 ton per TEU evaluated from the Jula case; $c_{\mathrm{re}}$ is the rate of variable emission cost increased per kilometer and is set to be 0.21014 SEK per kilometer; $V$ is the total shipping volume; $C_{\text {handling1 }}$ and $C_{\text {handling2 }}$ respectively refer to the total economic and emission costs of the terminal; $C_{\mathrm{v} \text {-handling1 }}$ and $c_{\mathrm{v} \text {-handling2 }}$ are the rates of variable costs increasing with the cargo volume; the $N_{\mathrm{ILUs}}$ is the number of the ILUs,

Table 2. The calculation model.

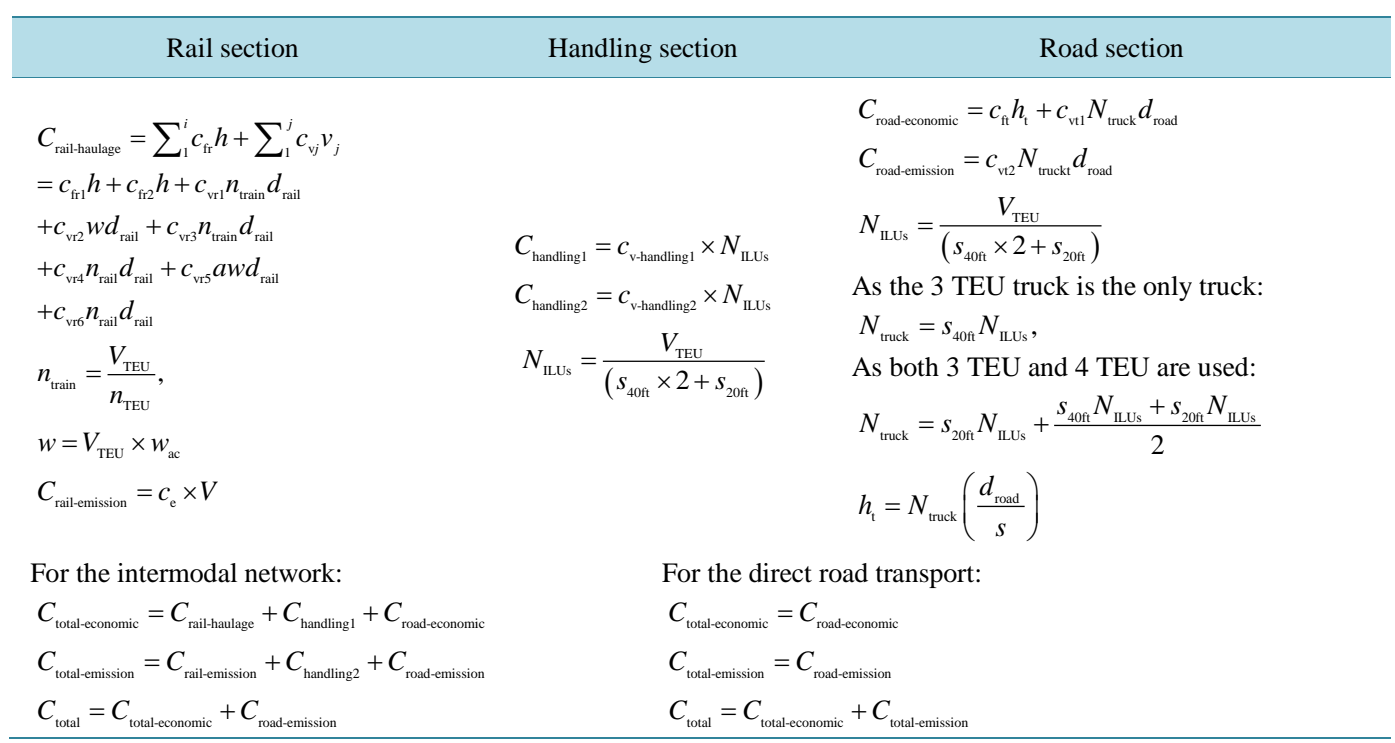


which is estimated based on the Jula case; $V_{\mathrm{TEU}}$ is the total volume per year (TEU); $\mathrm{s}_{40 \mathrm{ft}}$ is the share of the $40 \mathrm{ft}$ container; $s_{20 \mathrm{ft}}$ is the share of the $20 \mathrm{ft}$ container; $C_{\text {road-economic }}$ is the total economic costs of the road transport; $C_{\text {road-emission }}$ is the total emission costs; $c_{\mathrm{f}}$ is the fixed cost rate increasing with the required work hours; the $\mathrm{h}_{\mathrm{t}}$ is the required work hours; $c_{\mathrm{vt} 1}$ is the rate of variable economic costs increasing with the cargo volume; $\mathrm{c}_{\mathrm{vt} 2}$ is the rate of variable emission costs increasing with the cargo volume; $N_{\text {truck }}$ is the number of the shipments related to the truck; $d_{\text {road }}$ is the distance; $s$ is the speed of the truck based on Sweden's transport regulation.

\section{The Modal Application and Analysis}

\subsection{The Case Scenarios}

The aim of this case is to study the effects of a new transport solution for Jula's container transports between Port of Gothenburg and the central warehouse in Skara. The cargo is transported from Port of Gothenburg to the intermodal terminal in Falköping and subsequently loaded onto a truck with an exceedance of the maximum length of vehicles, which can carry two 40-foot containers simultaneously.

This dispensation for longer vehicles enables a competitive intermodal solution between Port of Gothenburg and Falköping intermodal terminal. The project is expected to provide opportunities for studies of haulage to and from the intermodal terminals and competitiveness of intermodal transport, and allow for generalizations on other similar situations.

Currently, the annual volume transported between Gothenburg and Jula's warehouse in Skara is expected to be about 7,000 containers (TEUs: twenty-foot units) on the road, which will be approximately 4 - 5000 trucks (one way) on the road (based on $>75 \%$ of the number of containers are $40 \mathrm{ft}$ ). The annual growth of the volume is estimated to be about $15 \%$ annually.

There are three alternative transport solutions of cargo between Gothenburg and Skara in the case of Jula. When we compare these scenarios the units must be defined. According to the standard container unit in transport, a $20 \mathrm{ft}$ container is referred to as 1 TEU (Twenty-foot Equivalent Unit) and a $40 \mathrm{ft}$ container is equivalent to 2 TEU. Consequently, the truck that can carry one $20 \mathrm{ft}$ container and one $40 \mathrm{ft}$ container is called a $3 T E U$ truck while the truck that can carry two $40 \mathrm{ft}$ containers simultaneously is called a 4 TEU truck. Therefore, the three alternative transport solutions refer to the IRT with a 3 TEU truck, which is the current network of Jula, the IRT with a 4 TEU truck, and the direct-road transport with a 3 TEU truck.

The three alternative transport networks are the scenarios illustrated in Figure 2. Scenario 1 refers to the solution that uses a 3 TEU truckin the PPH of the IRT. In Scenario 1, the cargo is transported from the port of Gothenburg to Falköping by train and from Falköping to Skara by general 3 TEU LHVs. As this kind of truck can carry maximum 3 TEU, such scenario is named 3 TEU Intermodal transport. By the way, this scenario is the one currently implemented by Jula. Scenario 2 refers to the solution that uses a 4 TEU truck (HCT) in the PPH of the IRT. In scenario 2, cargo is transported from Gothenburg to Falköping by train and from Falköping to Skara by $32 \mathrm{~m}$ (HCT). As this kind of truck can carry maximum 4 TEU, such scenario is named 4 TEU Intermodal transport. In scenario 3, the goods are transported from the port of Gothenburg to the terminal of Skara directly by general LHVs on highway E20. This scenario is named Direct Road transport, which was the solution previously used by Jula.

\subsection{Applying the Model}

The model is applied to the three scenarios of the Jula case making use of Swedish related data. For the purpose of the analysis, the volume of shipments is the independent variable. The default value of the basic parameter and variables defined above is shown in Table 3 for Jula. The other variables are derived on the volume. The default values are based on the Swedish Transport Administration [31] and the estimationsof truck cost and railway cost reported by Flodén respectively in 2007 [32] and 2011 [29].

The results of the calculation are described in Figure 3 and Figure 4 for drawing the change of the average cost depending on the shipment volume, and in Table 4 and Table 5 for giving the numeric results of sensitive analysis. Figure 3 shows that for the average economic cost of three scenarios the horizontal axis is the volume of TEUs and the vertical axis is cost in SEK. It is easy to see that Scenario 1 gets the top average economic cost because of the high fixed intermodal cost from transshipment and rail and the high variable cost from the 3 TEU truck in road transport. However, when we change the truck to 4 TEU (Scenario 2), the variable cost for road 


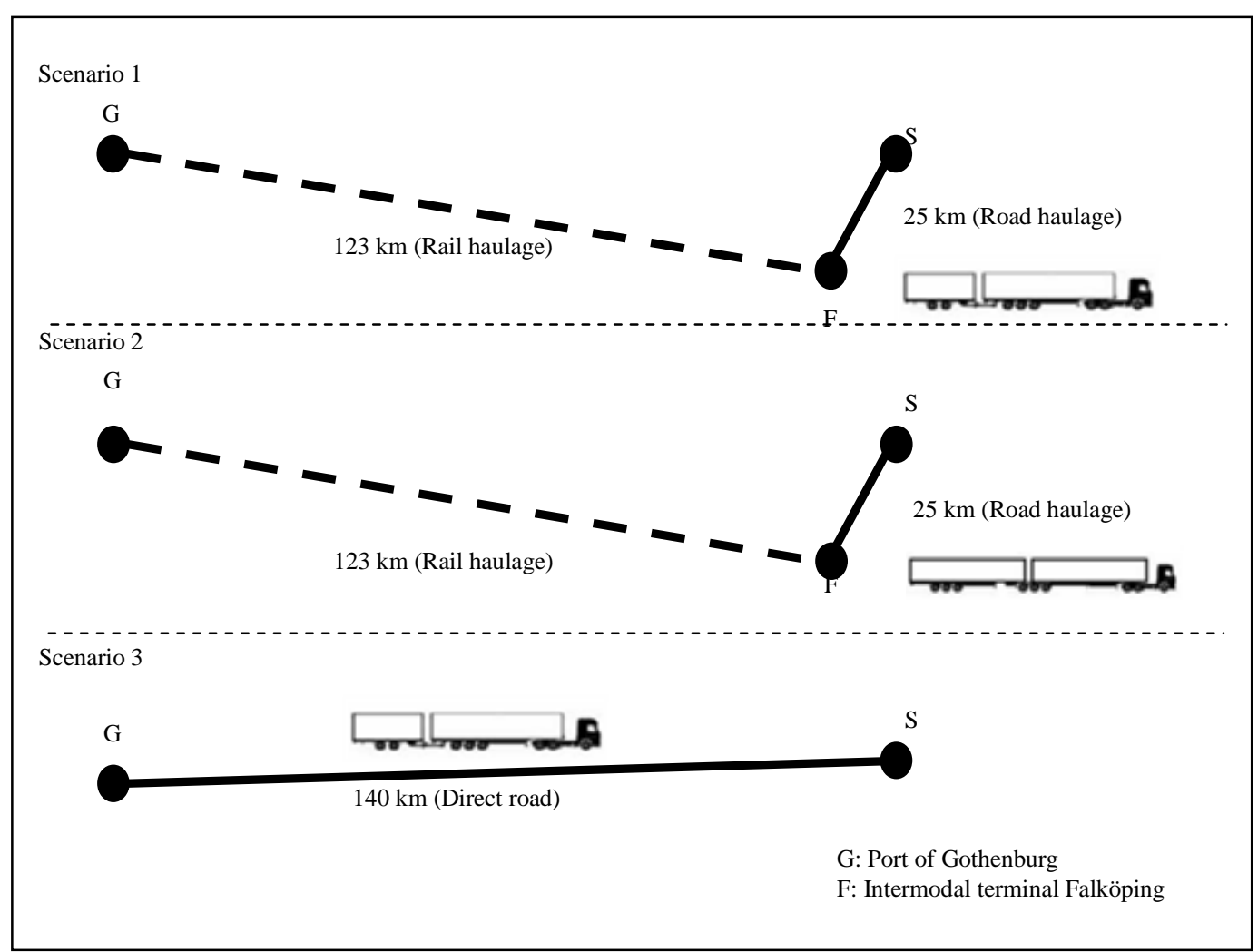

Figure 2. The network of scenarios.

Table 3. The default values from the case for sensitivity analysis.

$\begin{array}{ccc}c_{\mathrm{r} 1}=548.6 & c_{\mathrm{rv} 6}=7.5 & d_{\text {rail }}=123.14 \\ c_{\mathrm{r} 22}=782.13 & c_{\mathrm{re}}=0.21014 & d_{\text {road }}=25 \text { or } 140 \\ c_{\mathrm{rv} 1}=4.29 & c_{\mathrm{vhandling} 1}=257 & \mathrm{~s}=110 \text { or } 60 \\ c_{\mathrm{rv} 2}=0.0045 & c_{\mathrm{vhandling} 2}=14.22 & \mathrm{~s}_{40 \mathrm{ft}}=0.6934 \\ c_{\mathrm{rv} 3}=0.18 & c_{\mathrm{ft}}=374 & \mathrm{~s}_{20 \mathrm{ft}}=0.3066 \\ c_{\mathrm{rv} 4}=0.88 & c_{\mathrm{vt} 1}=4.6 & \\ c_{\mathrm{rv} 5}=0.661 & c_{\mathrm{vt} 2}=5.52 & \end{array}$

comes down, which makes the IRT more competitive. Furthermore, the average economic cost decreases when the volume of goods increases in IRT. In Scenario 3, as the direct road transport seldom has high fixed cost, the average cost is at bottom when the volume is less than 9500 TEUs, but the average cost will rise when the goods flow gets large because of the high road transport variable cost. Figure 4 shows the average total cost included the emission cost of the three scenarios. Each line shows the average cost. When the LHV is changed from 3 TEU to 4 TEU, the overall average cost comes down no matter how many TEUs are transported. As a result, there is no point of intersection of the line of scenario1 and the line of Scenario 2. In both Figure 3 and Figure 4, as the main types of direct road cost are variable, the line of scenario 3, which refers to the direct road average cost, is almost parallel to the horizontal axis. Table 4 gives the sensitive results of the cost reduction with LHVs and Table 5 provides the sensitive results of the economic cost and total cost dependent on the volume.

\subsection{Analysis}

Woxenius and Bärthel [29] reported that the key to explore the market of the IRT primarily lies in the 


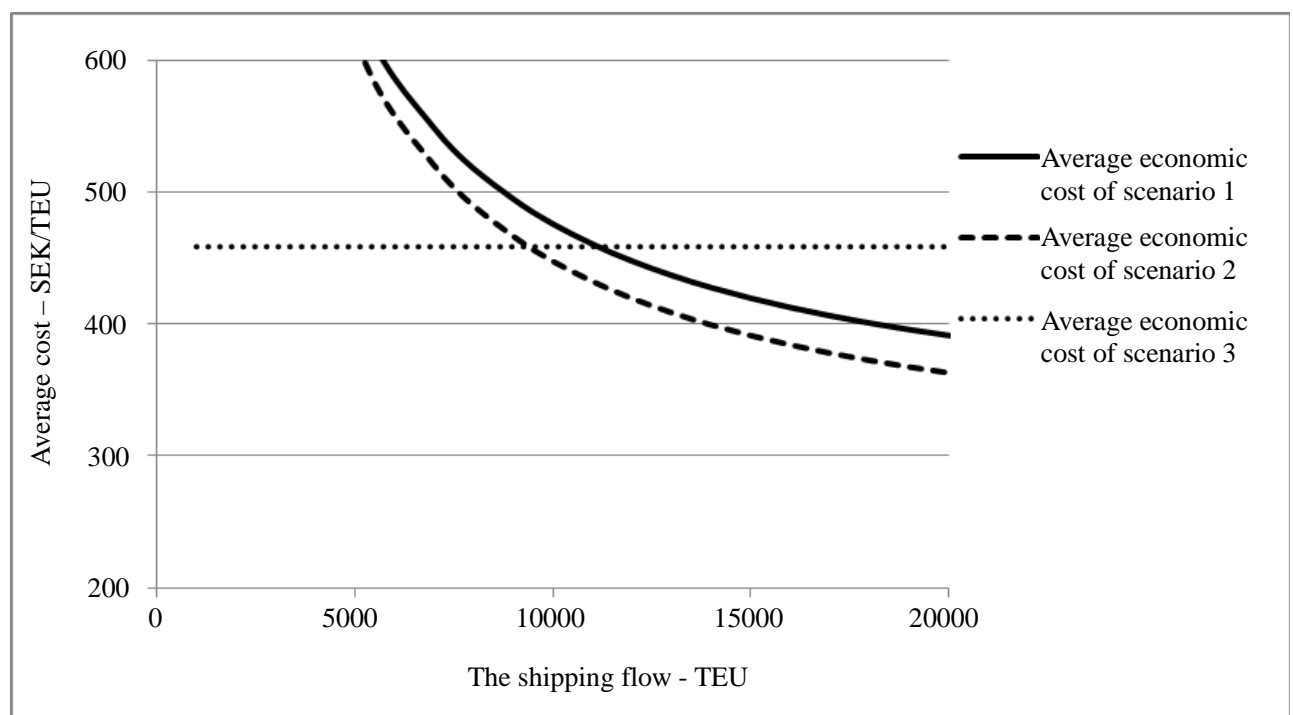

Figure 3. Dependence of the average economic costs of given scenarios on the volume of units.

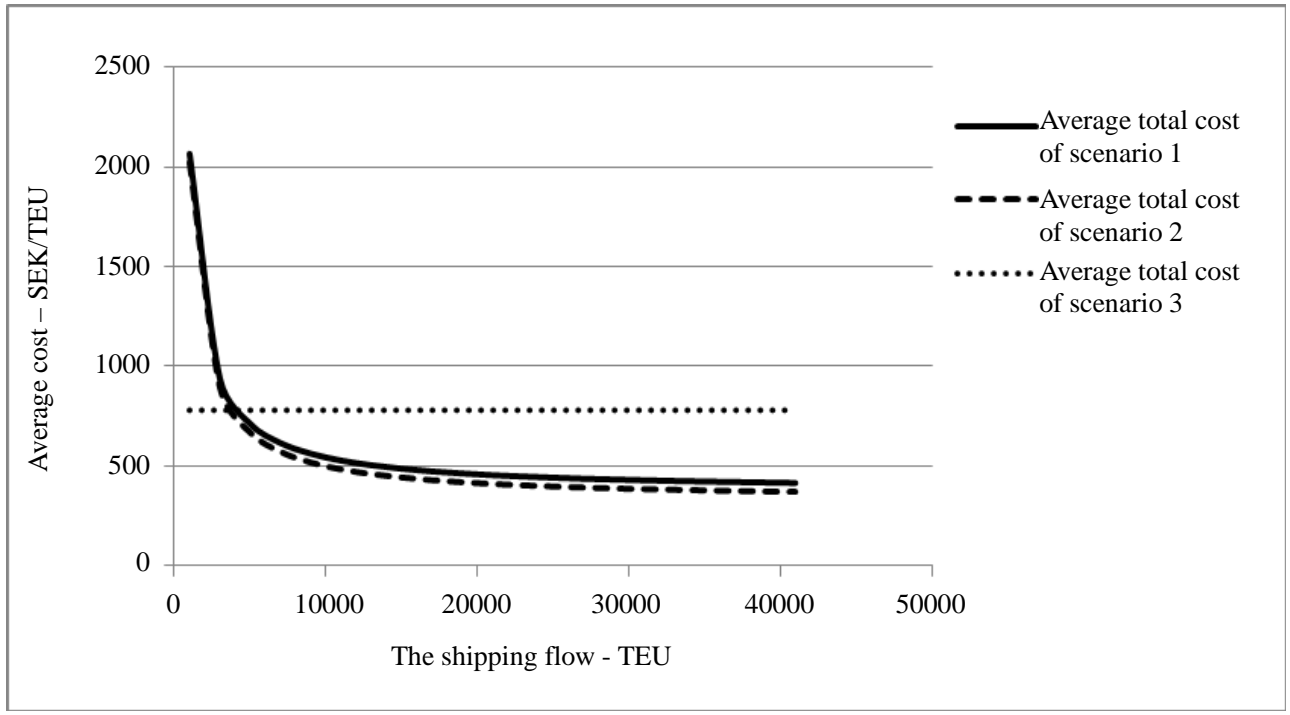

Figure 4. Dependence of the average total costs of given scenarios on the volume of units.

Table 4. The sensitive results of the cost reduction with LHVs.

\begin{tabular}{cc}
\hline Volume & Cost reduction \\
\hline 1000 & $1.44 \%$ \\
3000 & $3.25 \%$ \\
5000 & $4.39 \%$ \\
7000 & $5.16 \%$ \\
9000 & $6.15 \%$ \\
11000 & $6.48 \%$ \\
13000 & $6.75 \%$ \\
15000 & $6.97 \%$ \\
\hline
\end{tabular}


Table 5. The sensitive results of the economic and total costs.

\begin{tabular}{|c|c|c|c|}
\hline \multicolumn{4}{|c|}{ The economic cost } \\
\hline Volume (TEU) & Scenario 1 & Scenario 2 & Scenario 3 \\
\hline 1000 & 1999406 & 1971101 & 458608.7 \\
\hline 3000 & 2612841 & 2527927 & 1375826 \\
\hline 5000 & 3226275 & 3084753 & 2293044 \\
\hline 7000 & 3839710 & 3641578 & 3210261 \\
\hline 9000 & 4453145 & 4198404 & 4127478 \\
\hline 11000 & 5066580 & 4755229 & 5044696 \\
\hline 13000 & 5680015 & 5312055 & 5961913 \\
\hline 15000 & 6293449 & 5868881 & 6879131 \\
\hline 17000 & 6906884 & 6425706 & 7796348 \\
\hline 19000 & 7520319 & 6982532 & 8713566 \\
\hline \multicolumn{4}{|c|}{ The total cost } \\
\hline Volume (TEU) & Scenario 1 & Scenario 2 & Scenario 3 \\
\hline 1000 & 2065622 & 2021352 & 779176.2 \\
\hline 3000 & 2811490 & 2678678 & 2337529 \\
\hline 5000 & 3557358 & 3336004 & 3895881 \\
\hline 7000 & 4303226 & 3993330 & 5454233 \\
\hline 9000 & 5049094 & 4650656 & 7012586 \\
\hline 11000 & 5794962 & 5307982 & 8570938 \\
\hline 13000 & 6540830 & 5965308 & 10129291 \\
\hline 15000 & 7286697 & 6622634 & 11687643 \\
\hline 17000 & 8032565 & 7279961 & 13245996 \\
\hline 19000 & 8778433 & 7937287 & 14804348 \\
\hline
\end{tabular}

competition with unimodal road transport. In this section, we will not only calculate the performance of the LHVs related to the IRT based on the Jula case, but also will define the break-even of the different scenarios. The analyses of the break-even will indicate the competition between the IRT and unimodal road transport. The different break-evens we identify by shifting the scenario from scenario1 to scenario 2 imply how LHVs contribute to enhancing the competitiveness of the IRT and explore the IRT market.

The result in Figure 3 indicates that the average economic cost of intermodal network depends on the shipment volume and the average economic cost decrease with the increasing volume due to the high fixed cost of rail haulage. The average cost of direct road transport is assumed to be the same since there is an associated low fixed cost. This indicates that IRT enhances its competitiveness by increasing shipment volume and it is the competitive alternative to the direct-road transport beyond the break-even volume. The average economic cost of IRT with a 4 TEU truck decreases at a higher rate than the network of IRT with a 3 TEU truck. Thus the break-even volume of the IRT compared with the direct road is reduced from 11000 TEU to 9500 TEU. This means that the LHVs achieve the same distance exploring the IRT market over a smaller transport flow. Table 4 shows the sensitive results of the cost reduction from the comparison between Scenario 1 and Scenario 2 due to the LHVs. The result shows that the cost-decreasing rate increases with the volume.

The result in Figure 4 combines the average economic cost and the average external cost of three scenarios separately. When the volume of TEU is less than 3400, direct-road transport is the best solution. Otherwise, the 
IRT with 4 TEU is the best solution. As the total TEUs of goods transported from Gothenburg to Skara reached 8137 TEU in 2013, even the IRT of a 3 TEU is cost competitive compared to direct-road transport. The breakeven shifts from 3800 TEU to 3400 TEU indicating that the 4 TEU truck gains more benefits if costs of emissions are considered. Therefore, we believe that longer truck option enhanced the competitiveness of the IRT to gain more transport demand such as the market of smaller flow transport over shorter distance.

When also considering the external costs, it is obvious that scenario 2 is the most cost-efficient method when the traffic flow is over 3400 TEU. The break-even is 9500 TEU when just considering the economic cost, which indicates the IRT market will be significantly explored if we consider the emission costs. In other words, if the government decided to increase the degree of internalization of external costs, the IRT will become a competitive alternative in the EU transport market. For the case of Jula, the IRT with 4 TEU will bring benefits both in the environmental and economic aspects.

Given the analyses above, it is reasonable to draw the conclusion that the LHVs not only help Jula to achieve cost reduction but also explore the IRT market if the LHVs are used in the PPH. For Jula, the LHVs will get a 5.43\% reduction of the economic cost of the volume of 8137 TEU in 2013 and the benefit will increase with increasing transport demand. Meanwhile, as illustrated in the literature review, the IRT is competitive over long distance and large flows. The LHVs decrease the break-even compared with the direct road and thus explore the IRT market over a smaller transport flow and shorter distances.

\section{Conclusions}

This paper develops a model for analyzing the potential of longer and heavier vehicles related to pre- and post-haulage in the rail-truck intermodal transport chain. The literature review and case study both arrive at the conclusion that the LHVs contribute to improved efficiency, which can reduce both the economic and environmental costs of the PPH related to the IRT. The result of applying the model to the case of Jula shows that PPH plays an important role in the IRT by accounting for $21.5 \%$ of the total cost. Both economic and emission costs are lower in the IRT with LHVs compared to the current IRT of the Jula project. In the PPH, the LHVs save approximately $25.2 \%$ of economic costs and $24.1 \%$ of emission costs. The cost savings for the IRT chain is approximately $5.43 \%$ without considering the emission costs and about $7.53 \%$ for total cost achieved by LHVs. In addition, the LHVs help to enhance the competitiveness of the IRT compared with unimodal road transport. The break-even of the IRT and direct-road transport moved from 11000 TEU to 9500 TEU indicating that LHVs contribute to exploring the market of IRT over smaller flows. So far this thesis has pointed out the benefits of carrying out the LHVs in the PPH related to the IRT. Other opinions that should be considered are the possible consequences of the LHVs. From the literature review, there is no direct evidence that proves the LHVs would lead to bad consequences in the aspects of safety and the environment. However, there is a possibility that plenty of the rail transport would shift to the road mode if the LHVs are allowed for pure unimodal road transport. To control this risk, this thesis suggests using the LHVs in a specific IRT network.

In sum, the use of LHVs vehicles in PPH constitutes a large potential for intermodal rail-road transport in terms of increased efficiency, reduced need for investments, lower total energy consumption, and reduced emissions. The proposed cost calculation model can be used as a tool for evaluation and analysis related to intermodal transport solutions including PPH activities.

\section{References}

[1] OECD (2011) Moving Freight with Better Trucks Improving Safety, Productivity and Sustainability: Improving Safety, Productivity and Sustainability. OECD Publishing, Paris, 247-258.

[2] UIC (2012) 2012 Report on Combined Transport in Europe. Intermodal Union of Railways.

[3] European Commission (2006) Keep Europe Moving-Sustainable Mobility for Our Continent. Office for Official Publications of the European Communities, Brussels.

[4] Bergqvist, R. and Behrends, S. (2011) Assessing the Effects of Longer Vehicles: The Case of Pre- and Post-Haulage in Intermodal Transport Chains, Transport Reviews, 31, 591-602. http://dx.doi.org/10.1080/01441647.2011.584980

[5] European Commission (2012) Review of EU Rules Concerning Access to the EU Road Haulage Market and Access to the Occupation of Road Transport Operator.

[6] Ballis, A. andGolias, J. (2002) Comparative Evaluation of Existing and Innovative Rail-Road Freight Transport Terminals, Transportation Research Part A: Policy and Practice, 36, 593-611. 
http://dx.doi.org/10.1016/S0965-8564(01)00024-6

[7] Ballis, A. and Golias, J. (2004) Towards the Improvement of a Combined Transport Chain Performance. European Journal of Operational Research, 152, 420-436. http://dx.doi.org/10.1016/S0377-2217(03)00034-1

[8] Niérat, P. (1997) Market Area of Rail-Truck Terminals: Pertinence of the Spatial Theory. Transportation Research Part A: Policy and Practice, 31, 109-127. http://dx.doi.org/10.1016/S0965-8564(96)00015-8

[9] Bontekoning, Y.M., Macharis, C. and Trip, J.J. (2004) Is a New Applied Transportation Research Field Emerging?-A Review of Intermodal Rail-Truck Freight Transport Literature. Transportation Research Part A: Policy and Practice, 38, 1-34. http://dx.doi.org/10.1016/j.tra.2003.06.001

[10] UNECE (2001) Terminology on Combined Transport. Genua: The United Nations Economic Commission for Europe, New York.

[11] Nachtmann, H., Rossetti, M.D. and Taylor, G.D. (2004) WebShipCost Quantifying Risk in Intermodal Transportation, No. MBTC 2035.

[12] Lowe, D. (2006) Intermodal Freight Transport. Elsevier Butterworth Heinemann, Oxford.

[13] Woxeniusand, J. and Bärthel, F. (2008) Intermodal Road-Rail Transport in the European Union. The Future of Intermodal Freight Transport, Concepts, Design and Implementation. Edward Elgar Publishing, Cheltenham, 13-33.

[14] Macharis, C. and Bontekoning, Y.M. (2004) Opportunities for OR in Intermodal Freight Transport Research: A Review. European Journal of Operational Research, 153, 400-416. http://dx.doi.org/10.1016/S0377-2217(03)00161-9

[15] Kreutzbergerand, E., Macharis, C., et al. (2003) Is Intermodal Freight Transport More Environmentally Friendly Than All-Road Freight Transport? A Review. Proceedings of NECTAR Conference No. 7, Umeå, 13-15 June 2003, 13-15.

[16] Resor, R.R., Blaze, J.R. and Morlok, E.K. (2004) Short-Haul Rail Intermodal: Can It Compete with Trucks? Transportation Research Record: Journal of the Transportation Research Board, 1873, 45-52. http://dx.doi.org/10.3141/1873-06

[17] Bärthel, F. and Woxenius, J. (2004) Developing Intermodal Transport for Small Flows over Short Distances. Transportation Planning and Technology, 27, 403-424. http://dx.doi.org/10.1080/0308106042000287586

[18] Williams, B.M. and Hoel, L.A. (1998) Freight Planning Requirements Forinterstate Corridors. Transportation Quarterly, 52, 39-48.

[19] Morlok, E.K., Sammon, J.P., Spasovic, L.N. and Nozick, L.K. (1995) Improving Productivity in Intermodal Rail-Truck Transportation. In: Harker, P.T., Ed., The Service Productivity and Quality Challenge, Kluwer Academic Publishers, Dordrecht, 407-434. http://dx.doi.org/10.1007/978-94-011-0073-1_16

[20] Kim, N.S. and Van Wee, B. (2011) The Relative Importance of Factors That Influence the Break-Even Distance of Intermodal Freight Transport Systems. Journal of Transport Geography, 19, 859-875. http://dx.doi.org/10.1016/j.jtrangeo.2010.11.001

[21] Trip, J.J. and Bontekoning, Y. (2002) Integration of Small Freight Flows in the Intermodal Transport System. Journal of Transport Geography, 10, 221-229. http://dx.doi.org/10.1016/S0966-6923(02)00008-X

[22] Doll, C., Fiorello, D., Pastori, E., Reynaud, C., Klaus, P., et al. (2009) Long-Term Climate Impacts of the Introduction of Mega-Trucks, Study to the Community of European Railways and Infrastructure Companies (CER). Fraunhofer ISI (Study Co-Ordinator, Karlsruhe) TRT (Milan), NESTEAR (Gentilly), Fraunhofer-ATL (Nuremberg), Fraunhofer-IML (Dortmund), Karlsruhe.

[23] De Ceuster, G., Breemersch, T., Van Herbruggen, B., Verweij, K., Davydenko, I., et al. (2008) Effects of Adapting the Rules on Weights and Dimensions of Heavy Commercial Vehicles as Established within Directive 96/53/EC. European Commission.

[24] Newton, W., McKinnon, A., Knight, I., Palmer, A., Barlow, T., McCrae, I., et al. (2008) Longer and/or Longer and Heavier Goods Vehicles (LHVs): A Study of the Likely Effects if Permitted in the UK: Final Report. HIS, No. PPR 285.

[25] Amt, U.B. (2007) Longer and Heavier on German Roads: Do Megatrucks Contribute towards Sustainable Transport. Umwelt Bundes Amt Dessau.

[26] BAST (2006) Effects of New Vehicle Concepts on the Infrastructure of the Federal Truck Roadnetwork, Final Report. Federal Highway Research Institute (BAST).

[27] Janic, M. (2007) Modelling the Full Costs of an Intermodal and Road Freight Transport Network. Transportation Research Part D: Transport and Environment, 12, 33-44. http://dx.doi.org/10.1016/j.trd.2006.10.004

[28] Daganzo, C.F. (2005) Logistics Systems Analysis. Springer, Berlin.

[29] Flodén, J. (2011) Rail Freight Costs, Some Basic Cost Estimates for Intermodal Transport. Gothenburg University, Gothenburg. 
[30] Sutter, D. (2011) External Costs of Transport in Europe Update Study for 2008.

[31] Trafikverket (2014) Network Statement 2014. Trafikverket, Borlänge.

[32] Flodén, J. (2007) Modelling Intermodal Freight Transport. The Potential of Combined Transport in Sweden. Department of Business Administration Företagsekonomiska Institutionen.

\section{Appendix}

Table A1. The items of rail cost in Sweden.

\begin{tabular}{|c|c|c|c|}
\hline Items & Fixed or Variable costs & The fee rate (SEK) & The fee rate (evaluted 2014) SEK \\
\hline Salary cost & Fixed $\left(c_{\mathrm{f} 1}\right)$ & 517.14 SEK per hour [29] & 548.6 (assume 2\%increase per year) \\
\hline The fixed cost & Fixed $\left(c_{\mathrm{f} 2}\right)$ & 782.13 SEK per hour [29] & $\begin{array}{l}782.13 \text { (assume no increase } \\
\text { in equipment) }\end{array}$ \\
\hline $\begin{array}{l}\text { Train path for a } \\
\text { freight service }\end{array}$ & Variable $\left(c_{\mathrm{v} 1}\right)$ & 4.29 per train kilometre for high level [31] & 4.29 \\
\hline Track charge & Variable $\left(c_{\mathrm{v} 2}\right)$ & 0.0045 per gross tonne kilometre [31] & 0.0045 \\
\hline Operating charge & Variable $\left(c_{\mathrm{v} 3}\right)$ & 0.18 per train kilometre $[31]$ & 0.18 \\
\hline Accident charge & Variable $\left(c_{\mathrm{v} 4}\right)$ & 0.88 per train kilometre $[31]$ & 0.88 \\
\hline Electricity consumption & Variable $\left(c_{\mathrm{v} 5}\right)$ & $\begin{array}{l}0.0212 \mathrm{KWH} / \text { gross tonne kilometre, } \\
0.661 \text { per KWH }\end{array}$ & 0.661 \\
\hline Maintenance cost & Variable $\left(c_{\mathrm{v} 6}\right)$ & 7.5 per kilometre [29] & 7.5 (assume no increase) \\
\hline
\end{tabular}


Scientific Research Publishing (SCIRP) is one of the largest Open Access journal publishers. It is currently publishing more than 200 open access, online, peer-reviewed journals covering a wide range of academic disciplines. SCIRP serves the worldwide academic communities and contributes to the progress and application of science with its publication.

Other selected journals from SCIRP are listed as below. Submit your manuscript to us via either submit@scirp.org or Online Submission Portal.
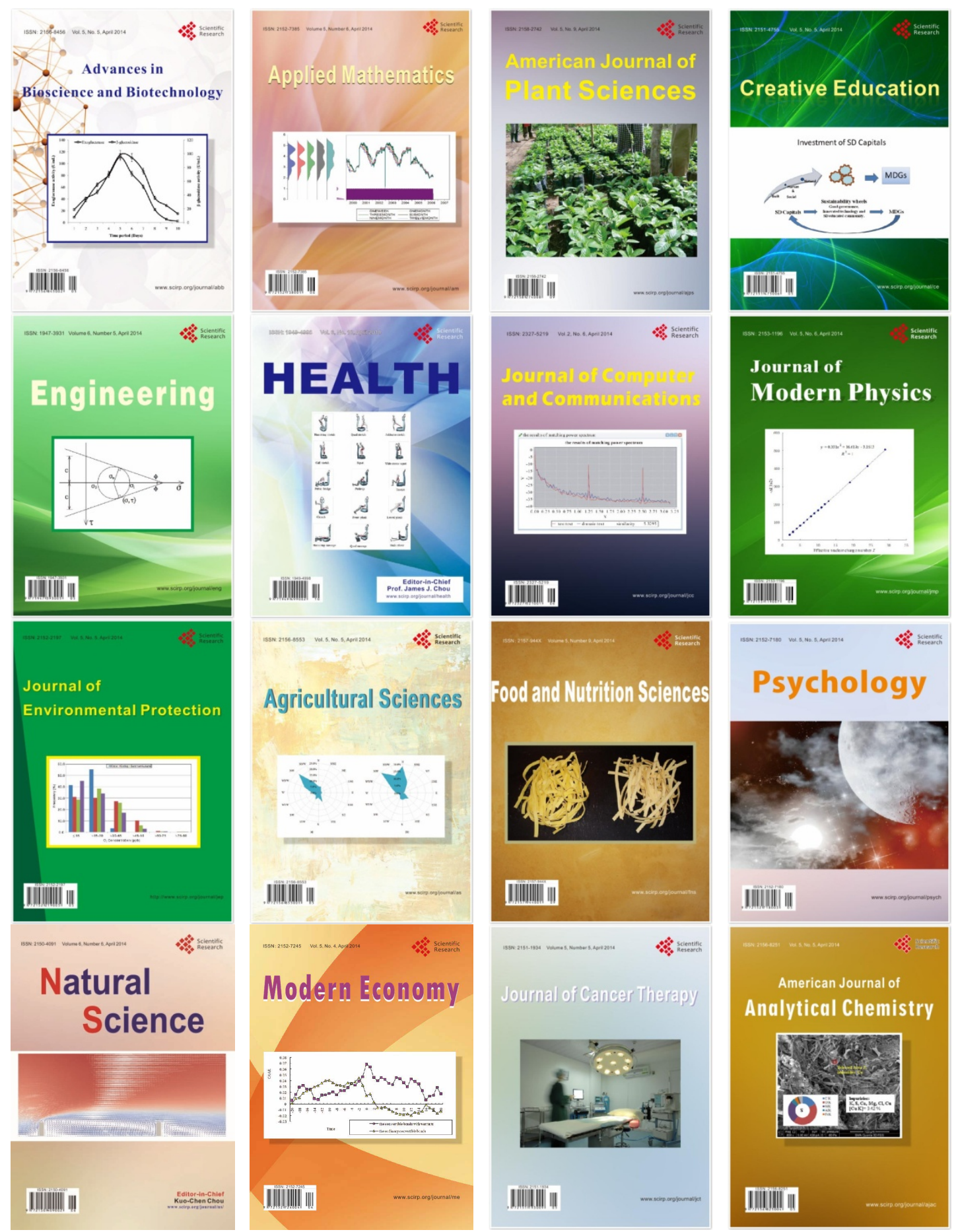